\title{
Tectonomagnetic study in the seismoactive area of Narmada-Son lineament, central India: Preliminary results on repeat field observations
}

\author{
S Y Waghmare ${ }^{1, *}$, S D Pimprikar ${ }^{2}$, P B Gawali ${ }^{1}$, L CARlo $^{1}$ and A G Patil ${ }^{1}$ \\ ${ }^{1}$ Indian Institute of Geomagnetism, New Panvel (W), Navi Mumbai 410 218, India. \\ ${ }^{2}$ Geological Survey of India, Sanjeevani Nagar, Jabalpur 482003 (M.P.), India. \\ *e-mail: waghmare@iigs.iigm.res.in
}

Repeated measurements of the total geomagnetic field on the five profiles have revealed a picture of stress-induced tectonomagnetic effect in the form of secular variation of the total geomagnetic field in the tectonically and seismically active area of Jabalpur and adjoining areas of the Narmada-Son lineament (NSL), central India. For this experiment, a reference base station was established within the study area at Jabalpur. Using proton precession magnetometers with a sensitivity of $0.1 \mathrm{nT}$, simultaneous measurements of total geomagnetic field were made annually at the base and all field stations. Five cycles of repeated observations have been performed between 2003 and 2007. For data analysis, a difference method has been applied and the residuals have been calculated as secular variations of the total geomagnetic field with values ranging from $\pm 0.1 \mathrm{nT}$ to about $< \pm 14.6 \mathrm{nT} / \mathrm{yr}$ over the different stations. The anomalies in secular variation of the total geomagnetic field may be related to anomalous accumulation of tectonic stresses and tensions on the deep fault zones and crustal blocks due to recent geodynamic processes and active geological inhomogeneities in the NSL.

\section{Introduction}

The study of geomagnetic changes associated with various kinds of tectonic activity such as earthquakes, volcanic eruption, gradual crustal movement and so on, was named as 'Tectonomagnetism' (Nagata 1969). The results of precise magnetic surveys, carried out repeatedly at exactly the same locations, have suggested that secular changes of the total geomagnetic field ' $\mathrm{T}$ ' to be of crustal origin, hence, rock magnetization changes are due to changes in their stress state. The movement of tectonic plates builds up tectonic stresses on faults and weaker zones for longer time in the Earth's crust. These tectonic stresses are associated with three types of effects. These are (1) dilatancy (e.g., Scholz et al 1973) (2) electrokinetic (e.g., Mizutani et al 1976) and (3) piezomagnetic (e.g., Stacey and
Johnston 1972). All these are considered as precursory phenomena. The piezomagnetic effect associated with tectonomagnetism or seismomagnetism comes into play as soon as stress build up starts and hence will introduce long-term precursors that can be detected through systematic repeated geomagnetic measurements carried out at regular intervals (6-12 months) for extended periods in a specified region (Rikitake and Honkura 1985).

The NSL has experienced more than 30 earthquakes in the magnitude range of $3.0-6.5$ on the Richter scale (Gupta et al 1997). A number of earthquakes of various magnitudes (M) on Richter scale have occurred in the past with epicenters in and around Jabalpur, these are $1846(6.5 \mathrm{M}), 1903$ (4.7 M), 1973 (3.7 M), 1993 (3.8 M), 1997 (6.0 M) and $2000(5.2 \mathrm{M})$ as reported by India Meteorological Department (1998) and Pimprikar and

Keywords. Tectonomagnetism; geomagnetic secular variation; stress; piezomagnetic; electrokinetic; geomagnetic repeat survey. 
Devarajan (2003). Keeping in mind the seismicity history in Jabalpur area, a project 'Tectonomagnetic study in Jabalpur-Kosamghat and adjoining areas in Central India' was launched by Indian Institute of Geomagnetism, Navi Mumbai, in 2002 .

\section{Geological and geophysical investigations in NSL}

The geology and tectonic background of central Indian region is greatly influenced by the eastwest trending NSL, which is a conspicuous linear tectonic feature about $1600 \mathrm{~km}$ long extending towards Murray ridge (Arabian Sea) and the eastern syntaxial bend of Himalayas (Mishra 1977). This feature is invariably visualized as a continental rift reactivated since Precambrian times (Choubey 1971). In contrast, Ghosh (1976) has considered the Narmada-Son lineament as representing an erosional post-Deccan Trap Narmada valley formed at the crest of a domal upwarp. Observing that the faults bounding the Narmada zone are believed to have played a significant role in the deposition of Vindhyan sediments (Meso-Neoproterozoic) on the northern side and Gondwana (Permo-Carboniferous) sediments on the southern side of Narmada zone, West (1962) concluded that the landmasses on either side of the lineament must have undergone relative vertical movement several times during the geological past. The boundary faults limiting this zone have been identified to the east of $76^{\circ} \mathrm{E}$, as Narmada north and Narmada south fault (Jain et al 1995). Major cities and towns along with geological and tectonic background of the NSL are shown in figure 1.

During the past few decades, several geophysical studies have been undertaken along this major lineament. Qureshy (1964) made qualitative studies of gravity anomalies along the lineament and concluded that the Satpura ranges in the western parts (associated with a gravity high) represent a horst-type structure. The Bouguer high suggests copious high-density material in lower crust, which might be the result of large-scale asthenospheric upwelling and basic intrusions along Moho, and in the crust. The large-scale asthenospheric upwelling south of Narmada appears to be related to several rift systems of these regions such as Tapti graben, Godavari graben, Satpura and SouthRewa-Mahanadi-Gondwana rifts, etc. (Mishra 1977). Verma and Banerjee (1992) have shown the Jabalpur Bouguer gravity high $\left(22^{\circ} 46^{\prime} \mathrm{N}, 78^{\circ} 48^{\prime} \mathrm{E}\right)$ is elliptical in shape and with an amplitude of 40 mgal, trends NE-SW and extends over a length of nearly $250 \mathrm{~km}$, with maximum width of nearly
$70 \mathrm{~km}$. The high gravity appears to be related to the tectonic framework of the NSL. A massive high-density intrusive body in the upper crust with density contract of $+0.1 \mathrm{~g} / \mathrm{cm}^{3}$ with respect to the normal crustal density is envisaged in order to explain the Jabalpur high. To understand the crustal structure and tectonic framework with its geophysical implication, five Deep Seismic Sounding (DSS) profiles, each about $250 \mathrm{~km}$ long, were shot across the NSL by National Geophysical Research Institute (NGRI), Hyderabad, India. Among these DSS profiles, only HirapurMandla profile passes through the present study area. The depth of Moho along the HirapurMandla DSS profile varies from $39.5 \mathrm{~km}$ near Tikaria to about $45 \mathrm{~km}$ at Narsighgarh. Narmada alluvial deposits cover the central part of DSS profile between Katangi and Jabalpur. In south, Deccan Trap is exposed between Jabalpur and Mandla. The DSS data has established a basement of uplifted horst zone between Katangi and Jabalpur (Kaila et al 1987). Satpura region is characterized by high heat flow as a result of both the conductive and advective heat transfer, with values that range from 70 to $100 \mathrm{~mW} / \mathrm{m}^{2}$ (Ravi Shankar 1988; Mahadevan 1994). On the basis of rheological models, thermo-mechanical structure of the central Indian shield of such a high heat flow regime do not support occurrence of deep crustal seismicity. Occurrence of Jabalpur earthquake very close to the crust-mantle boundary, provides a constraint on the thermo-mechanical structure of the central Indian shield, by favouring a low mantle heat flow (Manglik and Singh 2002). Magnetotelluric (MT) studies over the Damoh-Jabalpur-Mandla-Anjaneya profile, central India, by Gokarn and Singh (2000) show geoelectric structure in the depth range of $0-25 \mathrm{~km}$ and inferred a resistivity in a range of $2-700 \Omega \mathrm{m}$ in the Damoh-Jabalpur-Mandla region using two dimensional modeling. They interpreted the results as the lower crustal intrusive rising southeast from below Jabalpur into the upper crust leading to Tikaria gravity high. In another paper, Gokarn et al (2001) showed some vertical conductivity contrast as the geoelectrical cross-section in the depth range $30-40 \mathrm{~km}$ throughout the Damoh-Jabalpur-Mandla-Anjaneya profile and the resistivity variations are in a narrow range of $200-500 \Omega \mathrm{m}$. They interpreted the results that the conductivity anomaly and high gravity may have different causative mechanisms. The high conductivity may be due to the presence of crustal fluids, whereas the gravity high seems to be predominantly due to the upwarping of the Moho. A longwavelength magnetic anomaly map was compiled through rectangular harmonic analysis in central India; the NSL is characterized by a regional low, 

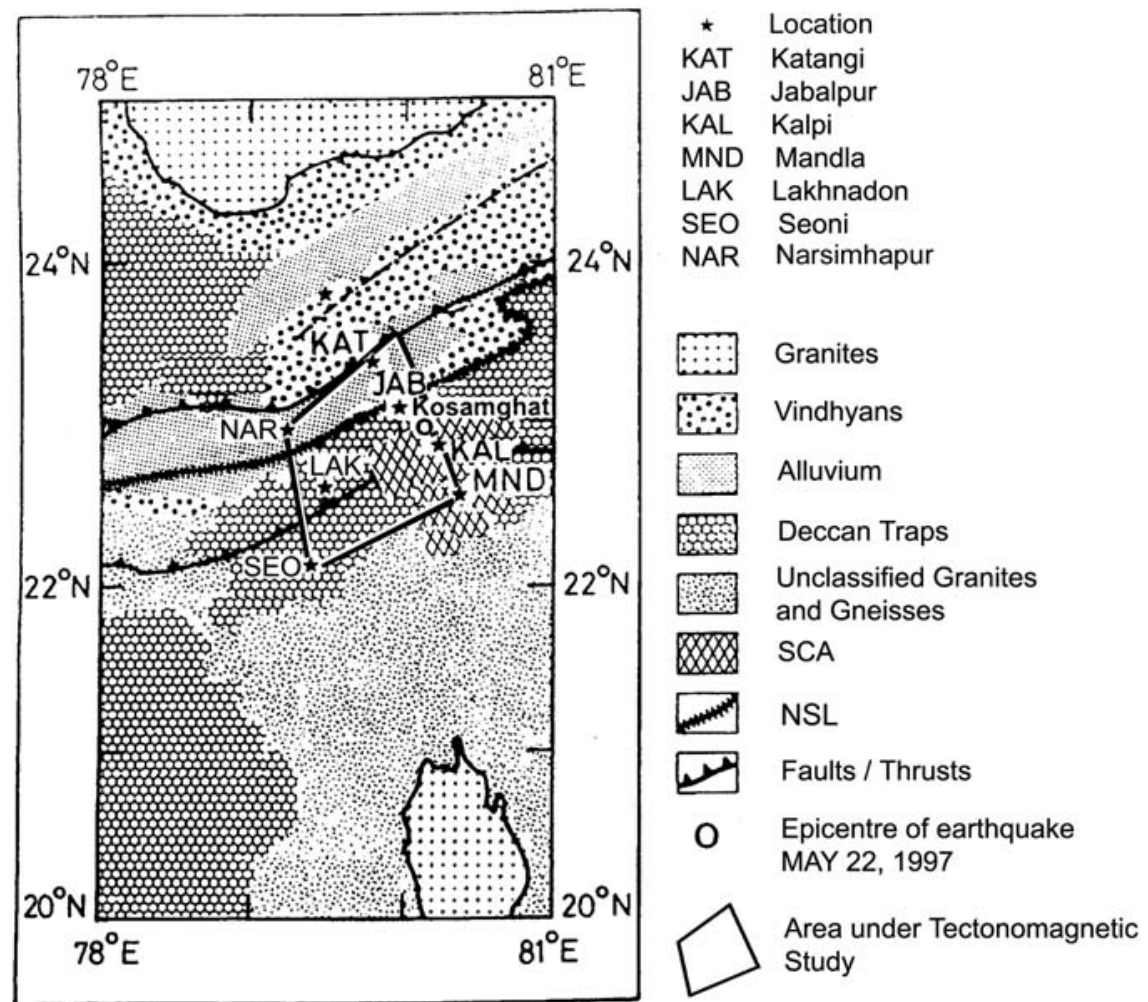

Figure 1. The principal tectonic elements of the Narmada-Son lineament (NSL) and adjoining areas (adopted from tectonic map of India, Eremenko and Negi 1968). The area under tectonomagnetic study is roughly drawn. Hatched area of Satpura conductivity anomaly (SCA) and location of cities and towns (*) and location (O) of Kosamghat, the epicenter of the Jabalpur earthquake May 22, 1997 are also shown in map.

embodying a weak positive anomaly (Arora and Waghmare 1984). A linear Geomagnetic Depth Sounding (GDS) experiment was carried out along Hirapur-Mandla-Bhandara magnetic profile for studying the lateral extent and geometrical configuration of Satpura electrical Conductivity Anomaly (SCA). The lateral extent of SCA is bounded between Jabalpur and Paraswada and its centre was located beneath Kalpi, which is shown as hatched area in figure 1. The SCA was interpreted as trapped fluids in the crust (Arora et al 1995; Waghmare et al 1996). The correlation of SCA with the Jabalpur earthquake of May 22, 1997 was shown by Waghmare (2003).

\section{Data collection during tectonomagnetic experiment}

A network of 70 field stations on the natural ground and far from man-made structures and with interdistances of less than $10 \mathrm{~km}$ were selected through geomagnetic measurements to ensure that stations are located in low-gradient areas. Sandstone pillars have been installed as stable benchmarks over which magnetometer sensor is placed for total geomagnetic field measurements. The locations of the stations comprise areas of Jabalpur, Katangi, Mandla, Seoni, Lakhnadon and Narsimhapur in Madhya Pradesh. Figure 2 shows a layout map of repeat survey stations covering five geomagnetic profiles and Narmada north fault and south fault are also roughly drawn in the figure. For measurements of total geomagnetic field intensity $T$, two drift-free and absolute measurable Proton Precession Magnetometers (PPMs) having a sensitivity of $0.1 \mathrm{nT}$ were used. One was deployed at base station and other used at field stations. Before an observation, PPMs were calibrated for exactly the same time by portable GPS receiver and sample scanning intervals were set for 15 seconds. Both the PPMs were operated simultaneously at the base and field stations for half an hour and a total of 120 values of total geomagnetic field intensity $T$ were recorded on auto mode and saved in PPMs memory, later downloaded to the Personal Computer at the base station. This procedure was adopted for covering all survey points and entire survey was completed within 30-40 days during each campaign. Five phases of surveys were completed starting from March-April 2003, which were repeated in February-March 2004, FebruaryMarch 2005, January-February 2006 and JanuaryFebruary 2007. 


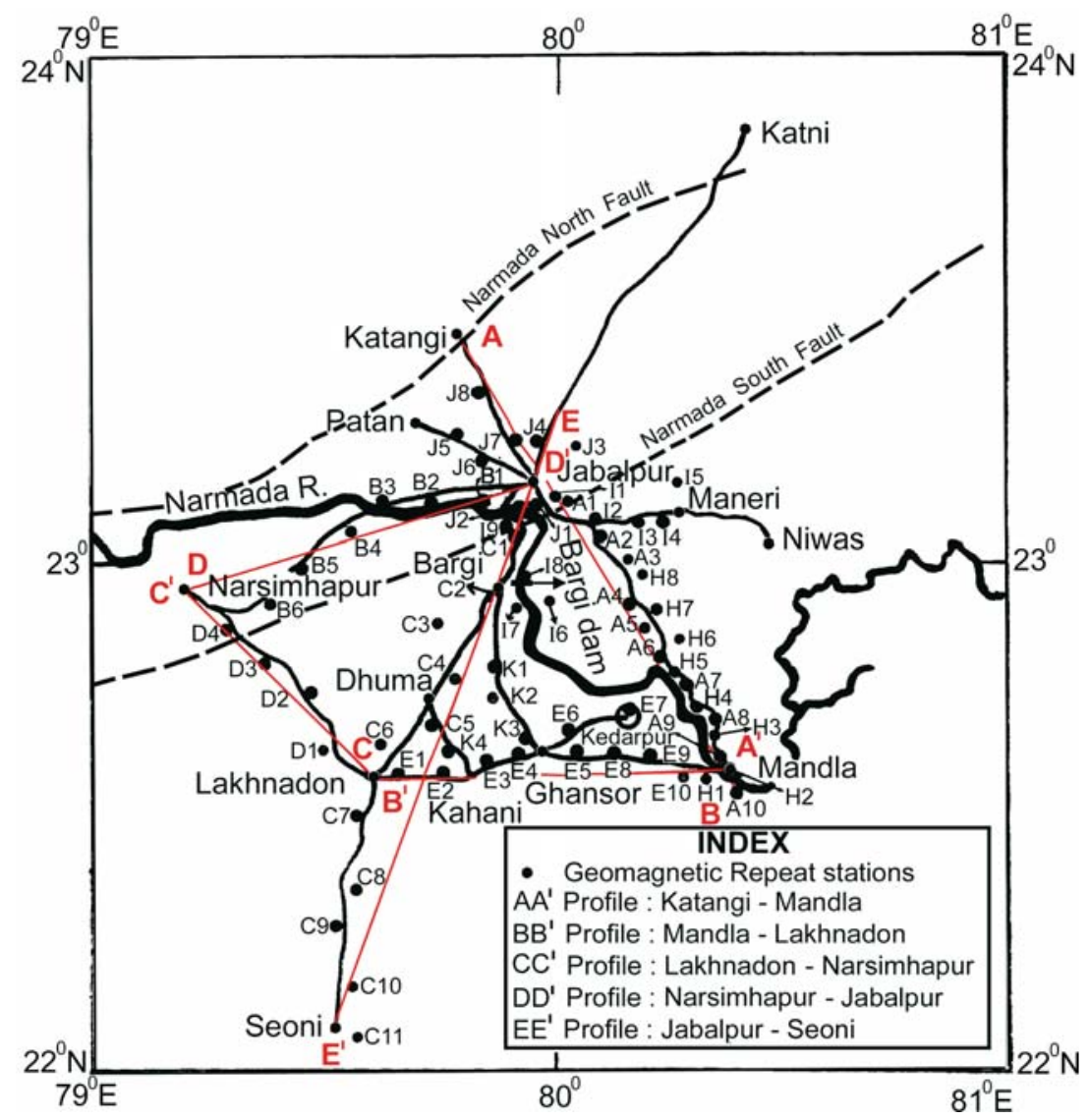

Figure 2. Map showing layout of geomagnetic repeat stations in Narmada-Son lineament, central India. Location of Narmada North Fault and Narmada South Fault (as reported by India Meteorological Department 1998) along with five geomagnetic profiles and station codes are shown in map.

\section{Data analysis}

The geomagnetic field is subjected to various kinds of variations with its origin in ionosphere and magnetosphere as well as within the Earth. However, these variations can approximately be treated as being spatially over areas of local extent. On the basis of this approximation, it is possible to detect changes associated with stress changes or other processes in the Earth by taking difference between the magnetic fields simultaneously observed at two or more stations (Honkura 1981). While studying electromagnetic induction within the Earth by natural external variation of magnetic field, Gough (1973) indicated that external fields incident on most of the Earth's surface are those of distant currents of ionosphere/magnetosphere and have wavelengths of thousands of kilometres. The external source field can be contaminated in the auroral and equatorial zone due to auroral and equatorial electrojets. Thus, external magnetic source fields may be considered as uniform to certain extent in the low and middle latitudes of the Earth. Moreover, Nishida et al (2004) have indicated that the contributions from Earth's core or ionospheric origin are ruled out as source mechanisms because of local distribution of the anomalous stations. Also, Honkura and Koyama (1976) pointed out that the distance between survey sites and reference base station should be less than $100 \mathrm{~km}$ to avoid apparent changes of the secular variations exceeding $1 \mathrm{nT} / \mathrm{yr}$. If we consider the external source field uniformity, according to Gough (1973) indications, our tectonomagnetic study area in the NSL is in the low latitudes between $22^{\circ} \mathrm{N}$ and $24^{\circ} \mathrm{N}$ and necessarily the external magnetic source field is uniform without any contamination due to the influence of electrojets. Also our reference base station is located in the study area with about $<100 \mathrm{~km}$ aerial distance from the field stations and the external source field will have similar contributions at the base and field stations. Hence, simple difference method can be applied to data analysis for eliminating the ionospheric/magnetospheric contributions.

However, the most disturbing factor is the presence of lateral inhomogeneities that exist in the crust, which cause electrical conductivity anomalies by electromagnetic induction from external varying geomagnetic field. The electromagnetic 
induction within the Earth is the frequency (period) dependent phenomenon, which follows the skin depth relationship $D s=0.5 \sqrt{ } \rho t \mathrm{~km}$, where $\rho$ is resistivity in $\Omega \mathrm{m}$ and $t$ is time in seconds (Gough 1992). There is a working rule that longer the time of external variation field deeper is the penetration of induced current within the Earth. But we are interested in probing crustal depth, so short period variation of the field can be used. For short period variations of micro-pulsation type, total magnetic field data for 10-minute averaging procedure is satisfactory, and the 'noise' component due to electrical conductivity inhomogeneities in the surrounding rocks does not contribute significantly to the variations of $\Delta T$ (Skovorodkin et al 1978). They also suggested that when high sensitivity $(0.1 \mathrm{nT})$ absolute proton precession magnetometers are used then the mean square error of a single observation of $\Delta T$ for 10 minutes is $\leq \pm 0.2 \mathrm{nT}$, when data samples are taken between 20 and 30. As per Skovorodkin et al (1978) indications, for the area under investigation, tectonomagnetic variation may be judged as significant when the change in $\Delta T$ exceeds $0.6 \mathrm{nT}$. It is not possible to determine the actual error of calculation in geomagnetic field secular variations at each site (Grabowska and Bojdys 2004). In this study, the proper data selection is necessary for the analysis, i.e., the precision measuring, and associated noise level that may be severely limited during detection of tectonomagnetic effect, which on theoretical considerations is not expected to exceed $10 \mathrm{nT}$ (Rikitake 1976; Zlotnicki and Cornet 1986). In the present case, a difference method for data analysis is followed (Skovorodkin et al 1978; Kuznetsova and Klymkovych 2001). The efficacy of the difference method and data reduction process was earlier tested with repeat surveys undertaken in seismically active region of Koyana, Maharashtra (Arora 1988) and in Garhwal Himalayas (Arora and Singh 1992).

Daytime data in terms of micro-pulsation (Pc5) type were used in the present study, which is ranging between 150 and 600 seconds (Samson 1991). Continuous string of 20 values, i.e., 300 seconds simultaneous data for the base and field station were selected for averaging and calculation of standard deviations. The difference was obtained by subtracting average value of base station from the average value of field station. Finally, a single value for a particular station is determined as the residual field, which can be interpreted as tectonomagnetic signal with respect to reference base station. Thus, the residuals were calculated for all field stations with respect to the reference base station for all repeated datasets. The theoretical interpretation is given as follows:
On the basis of a long series of repeat total geomagnetic field surveys, anomalies of temporal geomagnetic field changes $\Delta T=\Delta \Delta F$, i.e., tectonomagnetic anomalies are detected within a given time interval of observations. Within the profile and spatial observations of repeat surveys following quantities were followed: $F_{i}$ and $F_{o}$ - total geomagnetic field intensity in the $i$-th point and basic point (for all points of network), respectively. If $F_{i}^{*}$ and $F_{o}^{*}$ are values for the first cycle of the observations, then $\Delta F^{*}=F_{i}^{*}-F_{o}^{*}$. If $F_{i}^{* *}$ and $F_{o}^{* *}$ are values with a repeat cycle of the observation (within a chosen time interval, e.g., day, month, year, etc.), then $\Delta F^{* *}=F_{i}^{* *}-F_{o}^{* *}$. The tectonomagnetic anomaly is characterized by $\Delta \Delta F=\Delta F^{*}-\Delta F^{* *}$. If no local changes of the field of tectonomagnetic origin occurs, then $\Delta \Delta F \rightarrow 0$ (within the measurement errors and outer field identity). The values $\Delta \Delta F \neq 0$ indicate the availability of recent tectonic processes, which seem to be revealed due to repeat surveys (Kuznetsova and Klymkovych 2001).

\section{Results and discussion}

The statistical results of the observational data show that the mean standard deviation associated with residual field $\Delta T$ values range between 0.3 and $2 \mathrm{nT}$. The static secular variation anomalies of the geomagnetic field of the crustal origin range from $\pm 0.1 \mathrm{nT} / \mathrm{yr}$ to $\pm 14.6 \mathrm{nT} / \mathrm{yr}$ at different stations in various profiles. Despite lack of any seismic event during repeat survey period, the secular variation anomalies nevertheless have signified that the stresses are building in the crust of survey area. Our results seem to be reasonable compared to other results obtained in seismoactive region of Middle Asia as shown by Shapiro et al (1978), whose style of presentation is followed to present our results as shown in figures 3-8. Much of the interpretation to follow is based on the pattern resulting from statistical significant $\Delta T$ values and/or on the patterns emerging from group of stations. To resolve stress-related temporal magnetic changes of the crustal origin, two different techniques have been adopted for presenting the results as shown in figures 3-7(a) and in figures $3-7(\mathrm{~b})$. First one presents the departure of secular change in the residual total geomagnetic field from reference epoch (epoch 2003) as evaluated and examined in space domain. Thus, differences in secular changes in total magnetic field were obtained by subtracting second, third, fourth and fifth year's residual field from first year's residual field. Second technique is used to present the results as shown in figures $3-7(\mathrm{~b})$ where the residual field at each site are obtained 

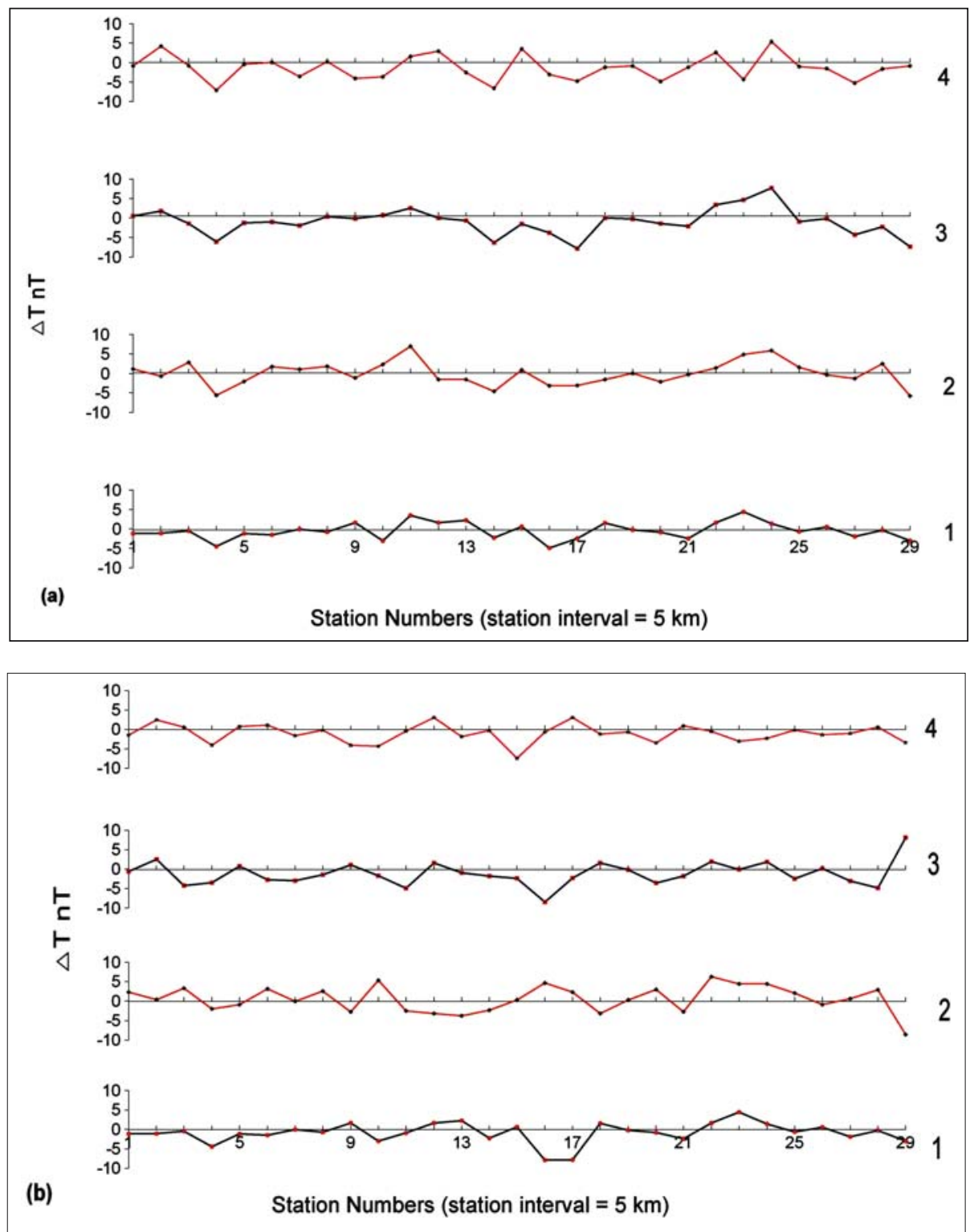

Figure 3. Change of the geomagnetic field $T$ along the Katangi-Mandla (AA') profile. (a) 1: $\Delta T$ difference (2003-2004); 2: $\Delta T$ difference (2003-2005); 3: $\Delta T$ difference (2003-2006); 4: $\Delta T$ difference (2003-2007). (b) 1: $\Delta T$ difference (2003-2004); 2: $\Delta T$ difference (2004-2005); 3: $\Delta T$ difference (2005-2006); $4: \Delta T$ difference (2006-2007).

as the difference between successive repeat surveys and are examined in space domain, i.e., with differencing second year residual field from first year and third year from second year and so on.

In majority of the cases, tectonomagnetic anomalies generally show relation with earthquakes and volcanic events. However, it is suggested that the gradual crustal movement can cause stress and tension in the vicinity of faults and weaker zones resulting in the magnetization changes and the signatures can be seen on the magnetic anomaly (Sasai 1991, 1994). If the slower crustal movement develops the stress gradually, then the central Indian crustal zone comprising NSL is most susceptible to stress development. Reason, the region is situated on a seismically active NSL, where stresses are continuously getting accumulated due to the movement of Indian plate in NE-SW direction (Gupta et al 1997). As is shown by Oshiman (1990), spatial pattern of negative and positive changes in total geomagnetic field can also be expected on a boundary between different blocks in the direction of crustal magnetization resulting in anomalous changes in the total geomagnetic field.

\subsection{Local geomagnetic field changes along $A A^{\prime}$ profile}

$\mathrm{AA}^{\prime}$ profile covers 29 stations between Katangi and Mandla with inter-station distance of about 
$5 \mathrm{~km}$. Figure 3 shows the change of geomagnetic field along the $\mathrm{AA}^{\prime}$ profile. Figure $3(\mathrm{a})$ shows four plots, i.e., $\Delta T$, difference for (2003-2004), (2003-2005), (2003-2006) and (2003-2007) respectively. The small-scale amplitude of the anomaly falls in the range of fraction to $8.5 \mathrm{nT}$ with positive and negative sign at some stations. It is evident that the smooth secular variations were observed between 2003 and 2006 but in the fourth plot more pronounced anomalous behaviour is seen in the $\Delta T$ difference of 2003-2007. Figure 3(b) also shows four plots, in which year-to-year changes of the geomagnetic field between 2003 and 2007, i.e., the $\Delta T$ differences (2003-2004), (2004-2005), (2005-2006) and (2006-2007), are plotted on the same scale as in figure 3(a). While comparing figure 3(a) and $3(\mathrm{~b})$, it is seen that in $3(\mathrm{~b})$ annual secular variations are more pronounced than in figure $3(\mathrm{a})$. It is speculated that distinctive pattern of $\Delta T$ differences observed in figure 3 may be because of some manifestation of stress and tension in NSL possibly causing local changes in the total geomagnetic field.

\subsection{Local geomagnetic field changes along $B B^{\prime}$ profile}

$\mathrm{BB}^{\prime}$ profile covers 13 stations between Mandla and Lakhnadon with inter-station distance of about $10 \mathrm{~km}$. Figure 4 shows changes in geomagnetic field along the $\mathrm{BB}^{\prime}$ profile. Figure $4(\mathrm{a})$ shows four plots of $\Delta T$ differences for (2003-2004), (2003-2005), (2003-2006) and (2003-2007). The amplitude of the geomagnetic anomalies falls in the range of fraction to $\pm 9.5 \mathrm{nT}$. The initial few stations of the profile show pronounced anomalies whereas the middle of the profile has smooth anomaly followed again by pronounced changes between station numbers 7-13. In figure 4(b), yearly $\Delta T$ difference have been taken for (2003-2004), (2004-2005), (2005-2006) and (2006-2007) where similar trends were observed like in figure 4(a) with reduced amplitude in geomagnetic anomalies. The area between Mandla and Lakhnadon is covered by Deccan Traps. Another fault is inferred at $13 \mathrm{~km}$ south of Lakhnadon called Gavilgarh fault (Jain et al 1995). Since NSL is under stress and this profile passes through NSL, stress-induced piezomagnetic effect may also influence total field geomagnetic anomaly.

\subsection{Local geomagnetic field changes along $C C^{\prime}$ profile}

This profile covers only 5 stations between Lakhnadon and Narsimhapur with inter-station spacing of about $10 \mathrm{~km}$. Figure 5 gives changes of the geomagnetic field along $\mathrm{CC}^{\prime}$ profile with an amplitude in the range of $\pm 0.2-9.6 \mathrm{nT}$. The
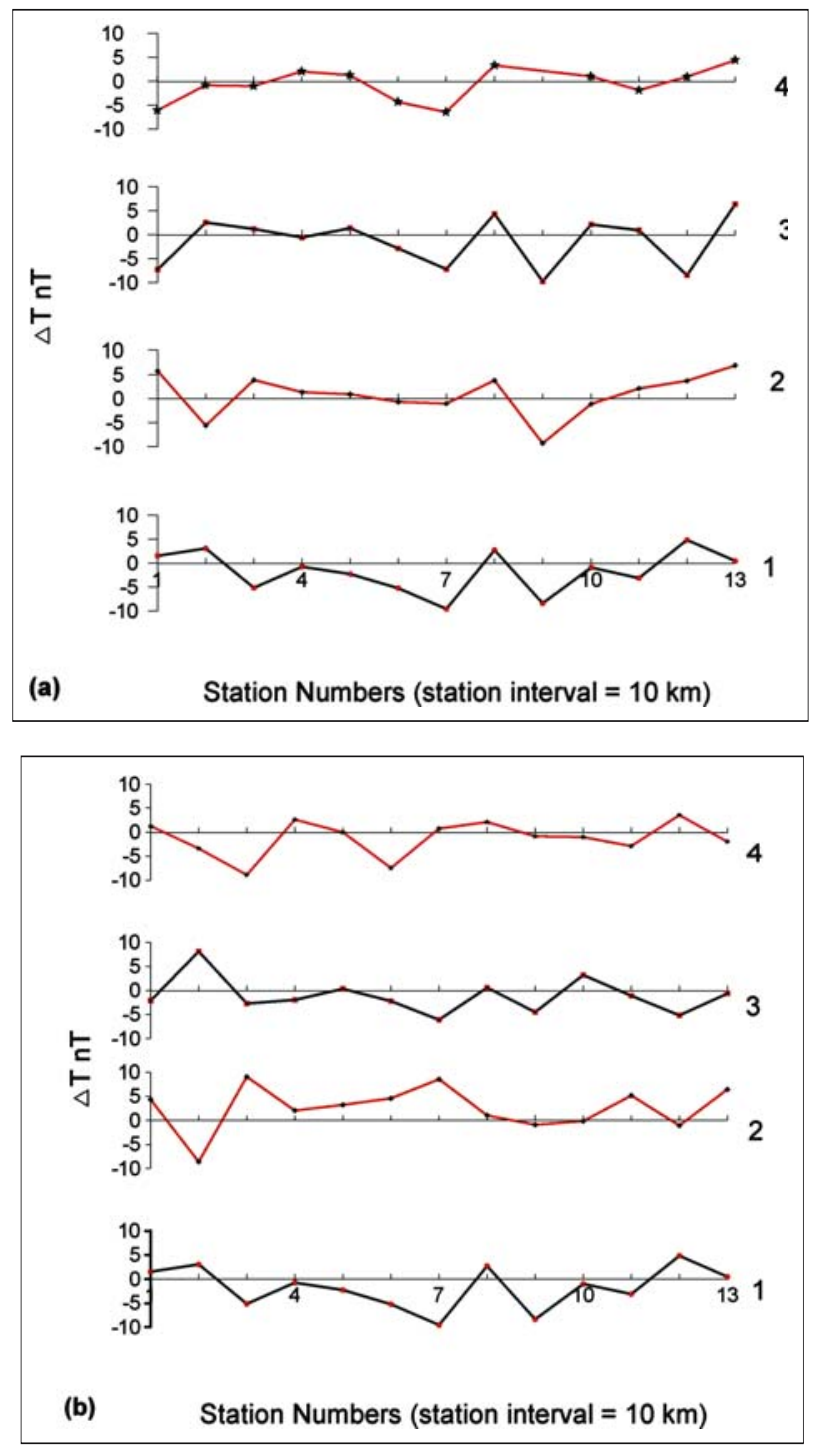

Figure 4. Change of the geomagnetic field $T$ along the Mandla-Lakhnadon $\left(\mathrm{BB}^{\prime}\right)$ profile. (a) $1: \Delta T$ difference (2003-2004); 2: $\Delta T$ difference (2003-2005); 3: $\Delta T$ difference (2003-2006); 4: $\Delta T$ difference (2003-2007). (b) 1: $\Delta T$ difference (2003-2004); $2: \Delta T$ difference (2004-2005); 3: $\Delta T$ difference (2005-2006); 4: $\Delta T$ difference (2006-2007).

difference of $\Delta T$ as shown in figure $5($ a) is less pronounced compared to the yearly changes in 5 (b) plots. The year-to-year changes in $\Delta T$ in this profile also may be related to the stress/tension building in NSL.

\subsection{Local geomagnetic field changes along $D D^{\prime}$ profile}

This is another small profile covering 8 stations between Narsimhapur and Jabalpur with interstation spacing of about $10 \mathrm{~km}$. Figure $6(\mathrm{a}$ and $\mathrm{b})$ gives four plots each with amplitude ranging from \pm 0.6 to $\pm 9.4 \mathrm{nT}$. In figure 6 (a) $\Delta T$ shows negative values for initial 4 stations but sudden positive jump is observed at the 5 th station of about $7-8 \mathrm{nT}$ 

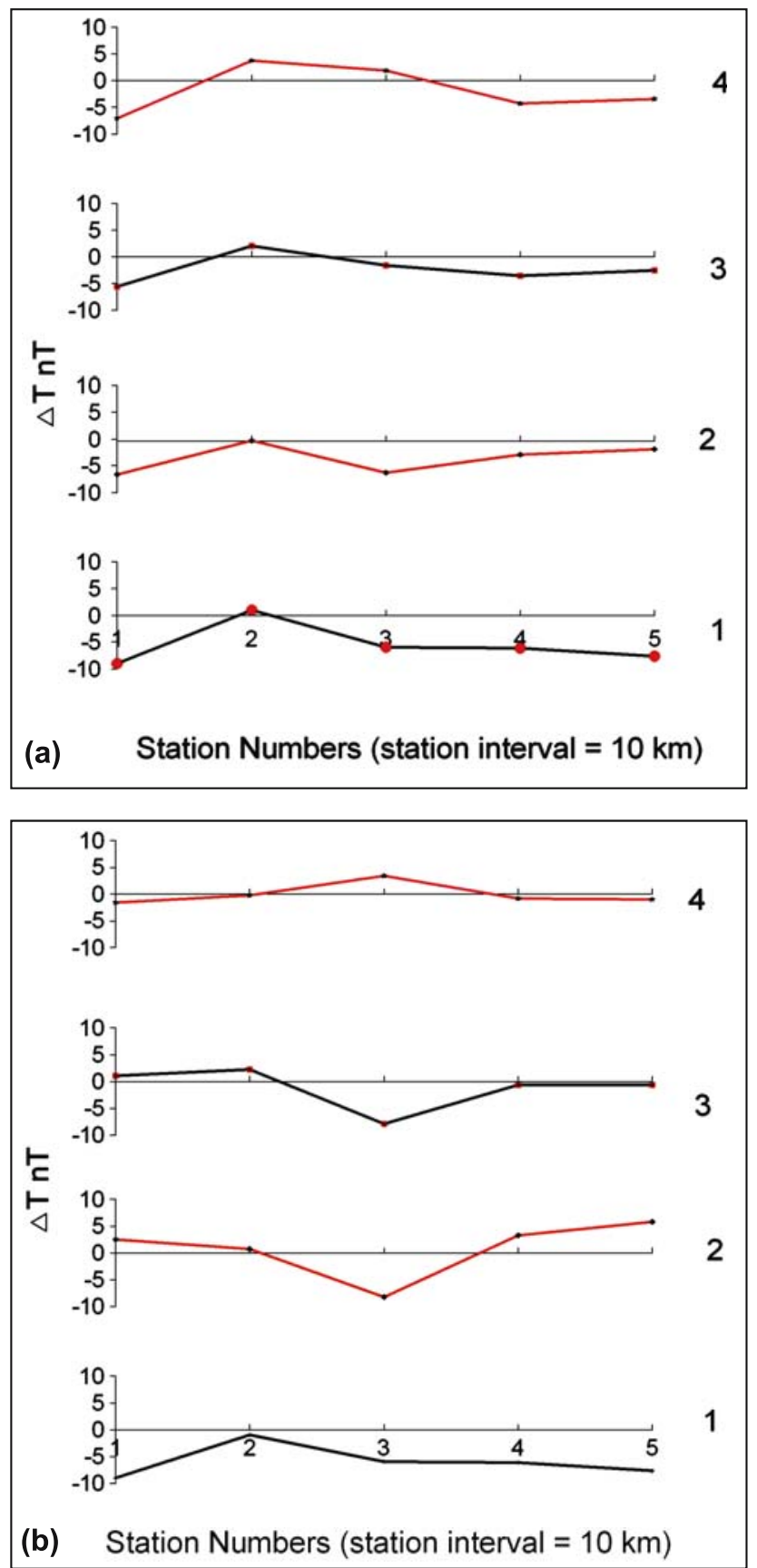

Figure 5. Change of the geomagnetic field $T$ along the Lakhnadon-Narsimhapur ( $\left.\mathrm{CC}^{\prime}\right)$ profile. (a) 1: $\Delta T$ difference (2003-2004); 2: $\Delta T$ difference (2003-2005); 3: $\Delta T$ difference (2003-2006); 4: $\Delta T$ difference (2003-2007). (b) 1: $\Delta T$ difference (2003-2004); $2: \Delta T$ difference (2004-2005); $3: \Delta T$ difference (2005-2006); 4: $\Delta T$ difference (2006-2007).

which is gradually suppressed further to about zero at the end of the profile. In case of figure 6(b) similar trend is observed but the $\Delta T$ difference for 2006-2007 is more suppressed in the 4th plot. The region is more or less in the Mahakoshal group with alluvial deposits between Narsimhapur and Jabalpur. Active Narmada South Fault is passing along this profile. Since whole area of NSL is under

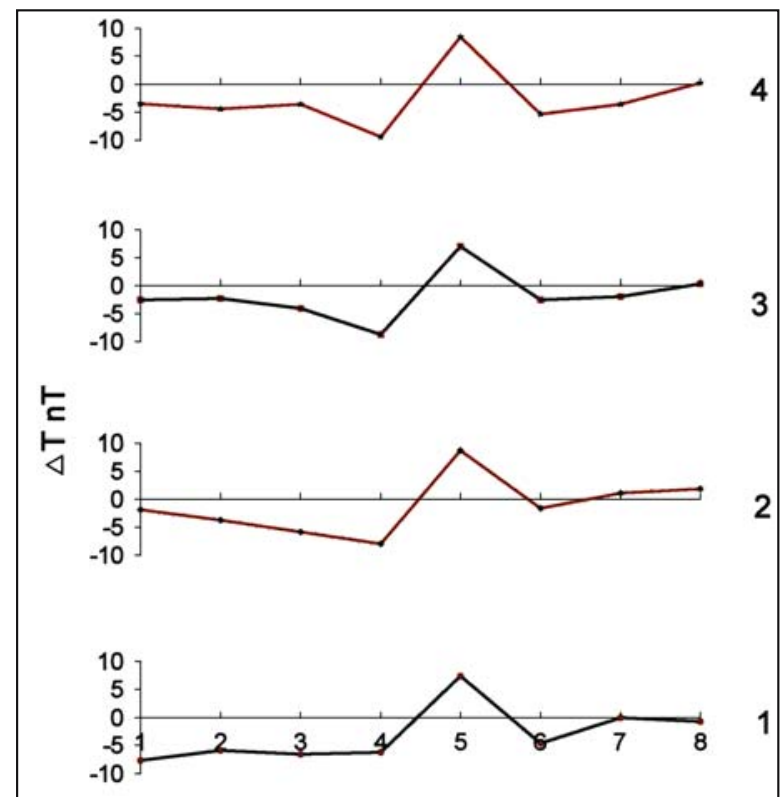

(a)
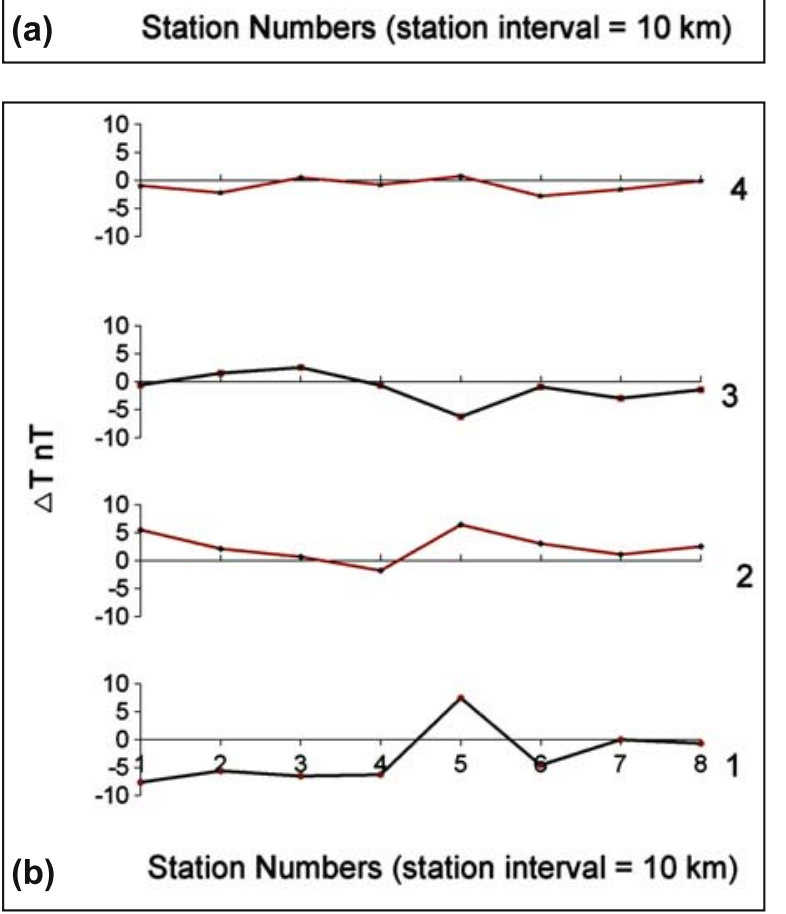

Figure 6. Change of the geomagnetic field along Narsimhapur-Jabalpur ( $\left.\mathrm{DD}^{\prime}\right)$ profile. (a) $1: \Delta T$ difference (2003-2004); $2: \Delta T$ difference (2003-2005); 3: $\Delta T$ difference (2003-2006); 4: $\Delta T$ difference (2003-2007). (b) 1: $\Delta T$ difference (2003-2004); $2: \Delta T$ difference (2004-2005); 3: $\Delta T$ difference (2005-2006); 4: $\Delta T$ difference (2006-2007).

stress it may cause changes in the total geomagnetic field along the profile.

\subsection{Local geomagnetic field changes along $E E^{\prime}$ profile}

This profile covers 19 stations between Jabalpur and Seoni and inter-station spacing is about $10 \mathrm{~km}$. 

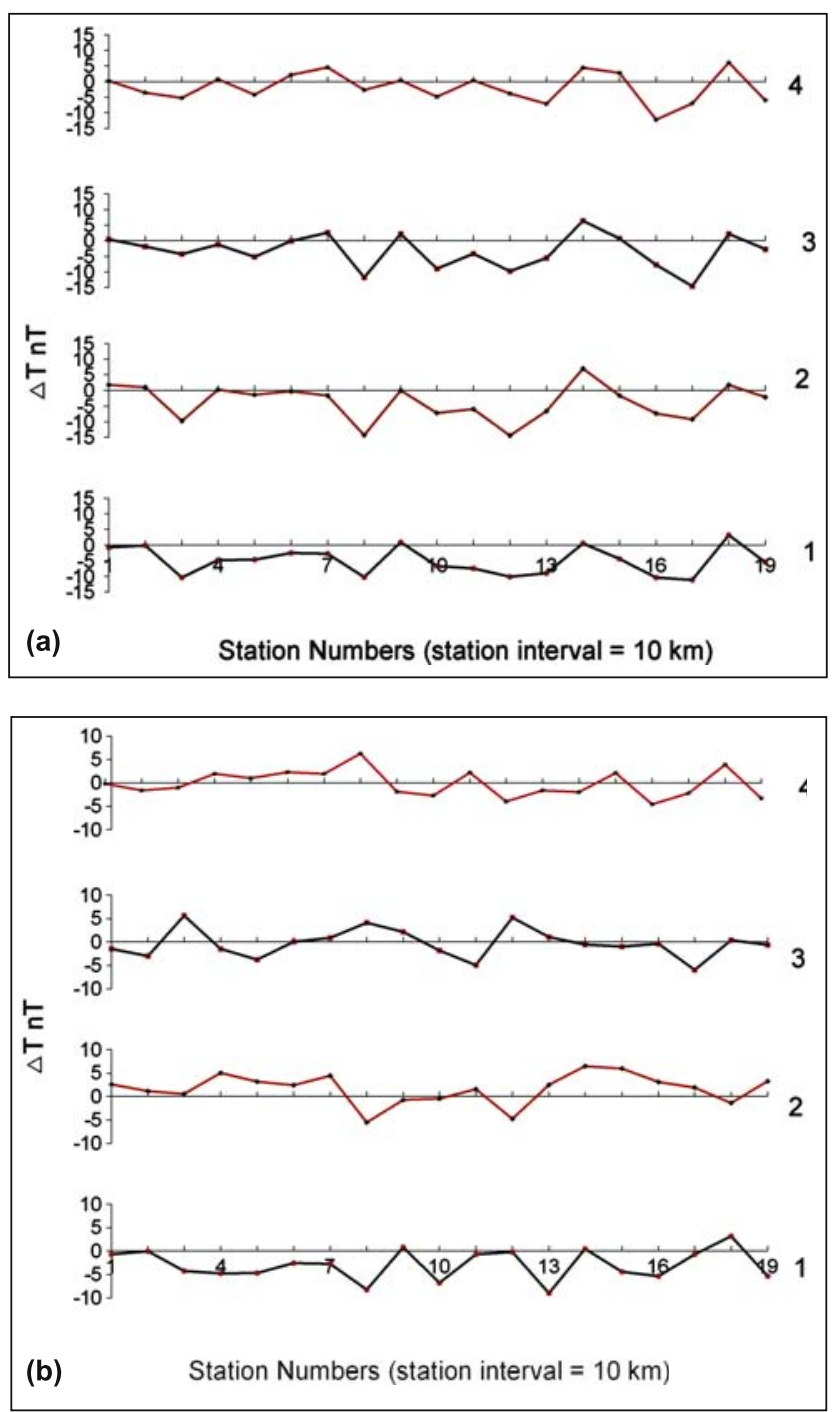

Figure 7. Change of the geomagnetic field along Jabalpur-Seoni (EE') profile. (a) 1: $\Delta T$ difference (2003-2004); 2: $\Delta T$ difference (2003-2005); 3: $\Delta T$ difference (2003-2006); 4: $\Delta T$ difference (2003-2007). (b) $1: \Delta T$ difference (2003-2004); 2: $\Delta T$ difference (2004-2005); 3: $\Delta T$ difference (2005-2006); 4: $\Delta T$ difference (2006-2007).

Figure 7 gives $\Delta T$ difference plots of 4 each for 7 (a) and 7(b) with amplitudes ranging from \pm 0.3 to $\pm 14.6 \mathrm{nT}$. In figure $7(\mathrm{a})$ the differences are taken from 2003 and the data collected in subsequent years. In figure $7(\mathrm{~b})$ year-to-year differences for the five surveys are taken from 2003 to 2007. While comparing 7(a) and 7(b) it is found that figure 7(a) depicts more pronounced secular variations of the total magnetic field than in figure 7(b). Jabalpur to Seoni area is mostly covered by Lameta sediments, Deccan basalt and intrusives (Jain et al 1995). The Archaeans include the older metamorphites, some ultramafic/basic intrusives and unclassified granite gneisses intruded at places by quartz, pegmatite and aplite veins in south of Seoni area (Naskar et al 2003). The swarm type seismic activities were experienced around Bamhori, Seoni district in April-May 2000. The hidden basement fault beneath the Deccan Traps may have existed there, causing swarm type seismic activity around Bamhori village (Pimprikar and Devarajan 2003). The secular changes in the total geomagnetic field may have related to stresses building due to active geological inhomogeneities in this profile.

No major seismic activity or volcanic activity was recorded during the tectonomagnetic observation period for March-April 2003 to JanuaryFebruary 2007. Hence, significant correlations have not been observed between seismic events and obtained values of secular variation of geomagnetic field in the survey area. Figures 3-7 suggest that the changes of the geomagnetic field in the survey area are probably anomalous. The histogram in figure 8 shows the values of residual total geomagnetic field $T$ are distributed in survey area with the function of number of stations with respect to epoch 2003 as well as successive years of changes. In figure 8 , the greatest change of the secular variation field were observed in 2003-2004 (a1) and in 2003-2006 (a3) and smallest changes of the field were observed in 2006-2007 (b4). It is interesting to note that in figure 8 , in diagram (a1) maximum 14 stations attained the values in a range of 0 to $-2 \mathrm{nT}$, in (a2) maximum 25 stations value reached a range of 0 to $-4 \mathrm{nT}$, in (a3) maximum 26 stations in a range of 0 to $-4 \mathrm{nT}$, in (a4) maximum 21 stations were placed in the range of 0 to $-4 \mathrm{nT}$, in (b2) maximum 19 stations found in the range of 2 to $4 \mathrm{nT}$, in (b3) maximum 20 stations appeared in the range of 0 to $-2 \mathrm{nT}$ and in (b4) maximum 24 stations attended a range of 0 to $-2 \mathrm{nT}$.

Seismicity associated with NSL is due to the strike-slip fault movement or thrust mechanism, consistent with the compressive stresses transmitted from plate boundaries as well as internal fabrics of crustal blocks (Mall et al 2005). Further they suggested that the influence of uplift processes such as horst-like structures in the form of Satpura mountain ranges that possibly originate through lithosphere-mantle interaction, perhaps are not uniform in magnitude and direction as the plate tectonic stresses. The obtained data gives evidence to stress-strained state variations in the crust of NSL leading to temporal anomalous variations of the geomagnetic field.

\section{Conclusion}

The space-time pattern of residual geomagnetic field around Jabalpur and adjoining areas in NSL indicates certain characteristic features which have been interpreted as stress change in the crust. 

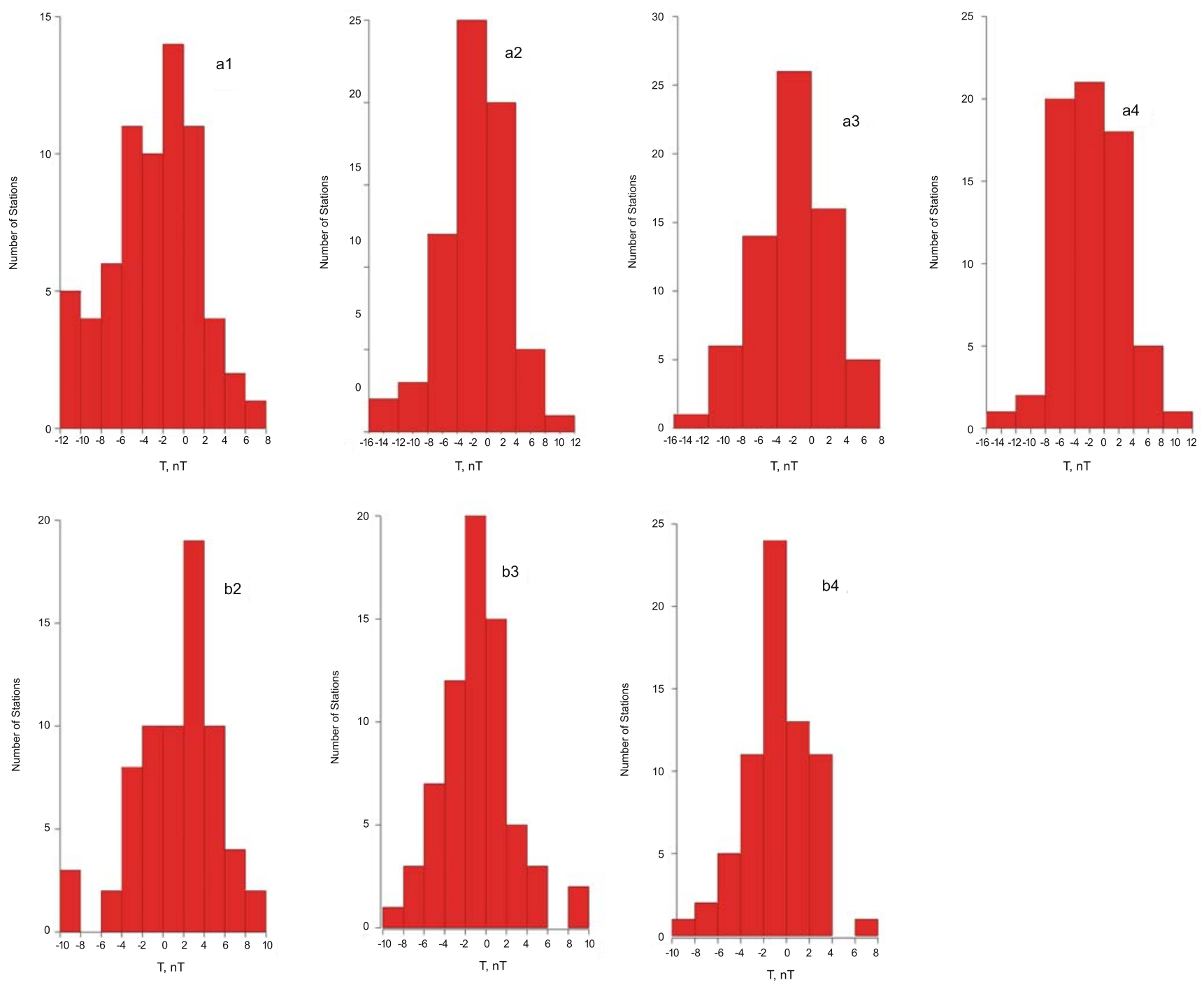

Figure 8. Histogram for total geomagnetic field $T$ distribution during 2003-2004 (a1), 2003-2005 (a2), $2003-2006$ (a3), 2003-2007 (a4), 2004-2005 (b2), 2005-2006 (b3), 2006-2007 (b4).

The small-scale secular variation anomalies may be a manifestation of tectonically active parts and joints of different tectonic crustal blocks of NSL. The secular variation anomalies of total geomagnetic field may have resulted in response to the gradual movement of Indian plate in NE-SW direction and collision with Eurasian plate building stresses and tension on the fault systems of the NSL zone. But, as no earthquake occurred in the surveyed region since the start of experiment, such general conclusions may be premature. However, data gathered in present surveys will help in investigating the tectonomagnetic effect of the impending seismic activity. Our annual observations will be continued to understand fully the tectonomagnetic processes operative in the area.

We have not yet reached the final goal for describing the generation mechanism for changes in total geomagnetic field in our study area.
However, secular changes in the total geomagnetic field in the crust may be originating from stressinduced tectonomagnetic (piezomagnetic) effect. This can be regarded as an indicator representing the crustal condition with respect to stresses building on deep fault zone and crustal blocks due to recent geodynamic processes and active geological inhomogeneities in the NSL.

\section{Acknowledgements}

The authors are thankful to the Director, Indian Institute of Geomagnetism, New Panvel (W), Navi Mumbai for encouraging and supporting the project 'Tectonomagnetic investigation in Jabalpur-Kosamghat area in Central India' and permission to publish this work. The authors are also thankful to the Director, Geological Survey 
of India, Jabalpur (M.P.) for providing necessary help during fieldwork. Mr S B Waknis and Mr B I Panchal are gratefully acknowledged for drawing the figures.

\section{References}

Arora B R 1988 Tectonomagnetic studies in India; In: Earthquake Prediction - Present Status (eds) Guha S K K and Patwardhan A M (Pune, India: Department of Geology, University of Poona) 53-62.

Arora B R and Singh B P 1992 Geomagnetic and geoelectric investigations for seismicity and seismotectonics of the Himalayan region; Geol. Soc. India Memoir 23 223-263.

Arora B R and Waghmare S Y 1984 Delineation of Longwavelength magnetic anomalies over Central India by Rectangular Harmonic analysis; Proc. Indian Acad. Sci. (Earth Planet. Sci.) 93 353-362.

Arora B R, Waghmare S Y and Mahashabde M V 1995 Geomagnetic depth sounding along the Hirapur-MandlaBhandara profile, Central India; Geol. Soc. India Memoir 31 519-535.

Choubey V D 1971 Narmada-Son lineament, India; Nature Phys. Sci. 232 38-40.

Eremenco N A and Negi B S 1968 Tectonic map of India, Oil and Natural Gas Commission, Dehradun, Printed at the 101(H.L.O.) printing group of Survey of India.

Ghosh D B 1976 The nature of Narmada-Son lineament, In: Seminar volume on Tectonics and Metallurgy of South and East Asia; Geol. Surv. India Misc. Publ. 34 119-132.

Gokarn S G and Singh B P 2000 Magnetotelluric technique; Research highlights in Earth System Science (eds) Varma O P and Mahadevan T M, DST's Spec. Published by Ind. Geol. Cong. 1 123-142.

Gokarn S G, Rao C K, Gupta Gautam, Singh B P and Yamashita M 2001 Deep crustal structure in Central India using Magnetotelluric studies; Geophys. J. Int. 144 685-694.

Gough D I 1973 The interpretation of magnetometer array studies; Geophys. J.R. Astr. Soc. 35 83-98.

Gough D I 1992 Electromagnetic exploration for fluids in the Earth's crust; Earth Sci. Rev. 32 3-18.

Grabowska T and Bojdys G 2004 Analysis of geomagnetic field along seismic profile $\mathrm{P} 4$ of the International project POLONAISE'97; Tectonophys. $\mathbf{3 8 3}$ $15-28$.

Gupta H K, Chadha M N, Rao M N, Narayana B L, Mandal P, Ravi Kumar M and Kumar N 1997 The Jabalpur Earthquake of May 22, 1997; J. Geol. Soc. India 50 85-91.

Honkura Y and Koyama S 1976 On a problem in earthquake prediction research based on the survey of the geomagnetic total intensity; Proc. Conductivity Anomaly Symp. Geol. Survey Japan 145-150.

Honkura Y 1981 Electric and magnetic approach to earthquake prediction; In: Current research in earthquake prediction I, DEPS02 (ed.) Rikitake T, Reidel D Publication Co., Center of Academic Publication, Tokyo, Japan, 301-383.

India Meteorological Department, New Delhi 1998 Jabalpur earthquake of 22 May 1997 and its aftershocks (a consolidated document), 70 pp.

Jain S C, Nair K K K and Yedekar D B 1995 Geology of the Son-Narmada-Tapti Lineament Zone in Central India; Geol. Survey India Spec. Publ. 10 1-154.
Kaila K L, Murthy P R K, Mall D M and Dixit M M 1987 Deep seismic sounding along Hirapur-Mandla profile, Central India; Geophys. J.R. Astr. Soc. 89 399-404.

Kuznetsova V and Klymkovych T 2001 Application of high-accuracy magnetometry to study recent geodynamic processes and earthquake precursors; Contributions of Geophysics and Geodesy 31 383-388.

Mahadevan T M 1994 Deep continental structure of India: A review; Geol. Soc. India Memoir. 28 1-562.

Mall D M, Singh A P and Sarkar D 2005 Structure and Seismotectonic of Satpura, Central India; Curr. Sci. 88 1621-1627.

Manglik A and Singh R N 2002 Thermomechanical structure of the Central Indian shield: Constraints from deep crustal seismicity; Curr. Sci. 82 1151-1157.

Mishra D C 1977 Possible extensions of the Narmada-Son lineament towards Murray ridge (Arabian Sea) and the eastern syntaxial bend of the Himalayas; Earth Planet. Sci. Lett. 36 301-308.

Mizutani H, Ishido T, Yokokura Y and Ohnishi S 1976 Electrokinetic phenomena associated with earthquakes; Geophys. Res. Lett. 3 365-368.

Nagata T 1969 Tectonomagnetism; I.A.G.A. Bull. 27 $12-43$.

Naskar D C, Mujumdar R K, Choudhury K and Das L K 2003 Magnetic profiles across NSL in part of Central India; Indian Minerals 57 53-60.

Nishida Y, Sagisaki Y, Takahashi K, Utsugi M and Oshima H 2004 Tectonomagnetic study in the eastern part of Hokkaido, NE Japan: Discrepancy between observed and calculated results; Earth Planets Space $\mathbf{5 6}$ 1049-1056.

Oshiman N 1990 Enhancement of tectonomagnetic changes due to non-uniform magnetization in the Earth's crust two-dimensional case studies; J. Geomag. Geolectr. 42 607-619.

Pimprikar S D and Devarajan M K 2003 Earthquake swarm activity around village Bamhori, Seoni District, Madhya Pradesh: A preliminary study; J. Geol. Soc. India 62 498-502.

Qureshy M N 1964 Gravity anomalies as related to regional tectonic of peninsular India; Rep. 22nd Int. Geol. Congr. New Delhi, India, Pt. IV 490-506.

Ravi Shankar 1988 Heat flow map of India and discussions on its geological and economic significance; Indian Miner. $4289-110$.

Rikitake T 1976 Earthquake Prediction (Amsterdam: Elsevier) $357 \mathrm{pp}$.

Rikitake T and Honkura Y 1985 Solid Earth Geomagnetism; Terra Scientific Publ. Co. Japan, 400 pp.

Samson J C 1991 Geomagnetic pulsations and plasma waves in the Earth's magnetosphere; In: Geomagnetism (ed) Jacobs J A (London: Academic Press, Harcourt Brace Jovanovich, Publ.) 4 481-590.

Sasai Y 1991 Tectonomagnetic modeling on the basis of the linear piezomagnetic effect; Bull. Earthq. Res. Inst. Univ. Tokyo 66 585-722.

Sasai Y 1994 Piezomagnetic fields produced by dislocation sources; Surveys in Geophysics 15 363-382.

Scholz C H, Sykes L R and Agarwal Y P 1973 Earthquake prediction: A physical basis; Science 181 803-809.

Shapiro V A, Pushkov A N, Abdullabekov K N, Berdallev E B and Muminov M Yu 1978 Geomagnetic investigations in the seismoactive regions of Middle Asia; J. Geomag. Geoelectr. 30 503-509.

Skovorodkin Yu P, Bezuglaya L S and Guseva T V 1978 Tectonomagnetic studies in Tajikistan; J. Geomag. Geoelectr. 30 481-486. 
Stacey F D and Johnston M J S 1972 Theory of the piezomagnetic effect in Titanomagnetic bearing rocks; Pageoph. 97 146-155.

Verma R K and Banerjee P 1992 Nature of continental crust along the Narmada-Son lineament inferred from gravity and deep seismic sounding data; Tectonophys. 202 375-397.

Waghmare S Y 2003 Correlation of Satpura electrical conductivity anomaly with the Jabalpur earthquake of May 22, 1997; J. Geol. Soc. India 62 74-82.
Waghmare S Y, Arora B R and Pecova J 1996 Estimation of structural geometry of Satpura conductivity anomaly through the Hilbert Transformation of magnetovariational fields; J. Assoc. Expl. Geophys. 17 165-175.

West W D 1962 The line of Narmada-Valleys; Curr. Sci. 31 $143-144$.

Zlotnicki J and Cornet F H 1986 A numerical model of earthquake induced piezomagnetic anomalies; J. Geophys. Res. 91 709-718.

MS received 24 December 2007; revised 25 February 2009; accepted 18 March 2009 